\title{
Adult Influenza A (H1N1) Related Encephalitis: A Case Report
}

\author{
Devinder Midha, Arun Kumar, Pratibha Vasudev, Zafar Ahmad Iqbal, Amit Kumar Mandal \\ Department of Pulmonology and Critical Care, MICU, Fortis Hospital, Mohali, Punjab, India
}

\section{Abstract}

The year 2009-2010 saw H1N1 influenza outbreaks occurring in almost all countries of the world, causing the WHO to declare it a pandemic of an alert level of 6. In India, H1N1 influenza outbreaks were again reported in late 2014 and early 2015 . Since then, sporadic cases of H1N1 influenza have been reported. H1N1 influenza usually presents itself with respiratory tract symptoms. In a minority of patients, abdominal symptoms may occur as well. Acute influenza-associated encephalopathy/encephalitis mostly occurs in the pediatric population, whereas in adults, it is a rare complication. The incidence of neurological complications appears to have increased after the $2009 \mathrm{H} 1 \mathrm{~N} 1$ influenza A virus pandemic. We would like to draw attention to an adult patient case who initially presented with respiratory symptoms but then deteriorated and developed encephalitis, which is rarely reported. As per literature reviewed by Victoria Bangualid and Judith Berger on PubMed, only 21 cases of neurological complications were found in adult influenza A patients, out of whom 8 had encephalopathy.

Keywords: Adult, encephalitis, H1N1

\section{INTRODUCTION}

Influenza is an acute, usually self-limited, febrile illness caused by infection with influenza type A or B virus. While respiratory symptoms are the most common, myositis, rhabdomyolysis, myoglobinuria, myocarditis, pericarditis, and central nervous system (CNS) involvement have all been described with influenza virus infections. ${ }^{[1]}$ Influenza related encephalitis/encephalopathy is more common is paediatric population, however neurological complications appears to have increased after 2009 pandemic ${ }^{[2-3]}$ Only eight cases with adult influenza A related-encephalopathy has been reported by Victoria Bangualid and Judith Berger.$^{[4]}$ CNS complications may manifest as encephalopathy, seizures, and Guillain-Barré Syndrome..$^{[-8]}$ The diagnosis is difficult because there is no uniform clinical presentation; influenza virus is rarely detected in cerebrospinal fluid (CSF) and may no longer be detectable in respiratory samples when the patient presents with neurological symptoms. ${ }^{[9]}$ We would like to report a patient with adult H1N1 influenza, who developed encephalitis.

\section{Case Report}

A 76-year-old, an elderly female in her mid 70s, was admitted to our Intensive Care Unit with chief complaints of sore throat,

\begin{tabular}{|l|l|}
\hline \multicolumn{2}{|c|}{ Access this article online } \\
\hline Quick Response Code: & Website: \\
\hline & www.ijccm.org \\
\hline & \\
\hline
\end{tabular}

sneezing, and fever for the last 7 days, along with oliguria during the last 3 days. She was initially treated at a district hospital with macrolides, antipyretics, and aminoglycosides. Oseltamivir $75 \mathrm{mg}$ bd was initiated 1 day prior to admission. Her comorbidities included hypertension and rheumatoid arthritis.

The patient was on tablet methotrexate which she had left 2 months prior to admission. Her chest radiograph was suggestive of right-sided pneumonia.

On admission, she was conscious, alert, hypotensive, and maintaining saturation on room air. Her mean arterial pressure improved after fluid resuscitation. Her initial laboratory results showed thrombocytopenia $(63,000 / \mu 1)$, a deranged renal profile (blood urea nitrogen $-38 \mathrm{mg} / \mathrm{dl}$, creatinine $2.1 \mathrm{mg} / \mathrm{dl}$ ), and hyponatremia $(124 \mathrm{mg} / \mathrm{dl})$. Her total leukocyte count, liver functions, and coagulation profile were within normal limits. Chest X-ray showed bilateral homogenous opacities in all lung fields. Her antibiotic regimen was modified to

Address for correspondence: Dr. Devinder Midha, Department of Pulmonology and Critical Care, MICU, $3^{\text {rd }}$ Floor, Fortis Hospital, Mohali - 160 062, Punjab, India. E-mail: devindermidha@gmail.com

This is an open access journal, and articles are distributed under the terms of the Creative Commons Attribution-NonCommercial-ShareAlike 4.0 License, which allows others to remix, tweak, and build upon the work non-commercially, as long as appropriate credit is given and the new creations are licensed under the identical terms.

For reprints contact: reprints@medknow.com

How to cite this article: Midha D, Kumar A, Vasudev P, Iqbal ZA, Mandal AK. Adult influenza A (H1N1) related encephalitis: A case report. Indian J Crit Care Med 2018;22:384-7. 
intravenous carbapenems and doxycycline along with oral oseltamivir. Sputum samples were sent to rule out viral pneumonia. A high-resolution computed tomography (CT) was made which showed multiple areas of crazy paving, dense consolidation in the right lower lung lobe along with mediastinal lymphadenopathy, and bilateral axillary lymph nodes [Figure 1].

On day 2 of admission, she developed respiratory distress. Viral myocarditis was ruled out with a negative troponin $T$ and raised pro-BNP levels $(1300 \mathrm{pg} / \mathrm{ml})$. She was supported with noninvasive ventilation and diuretics. She did show clinical improvement with the above interventions.

She was reported to be real-time polymerase chain reaction positive for pandemic influenza A (H1N1) in 2009. Her antibiotics were de-escalated and she was continued on tablet oseltamivir $150 \mathrm{mg}$ bd. Sequential chest X-rays showed worsening with bilateral consolidation. She developed severe acute respiratory distress syndrome (ARDS) requiring invasive ventilation. She was kept sedated and paralyzed with fentanyl, midazolam, and vecuronium infusion in view of $\mathrm{p} / \mathrm{f}$ ratio $<100$ suggestive of severe ARDS. She developed hemodynamic instability which was managed with fluids and vasopressors.

Over the next few days, the patient started showing signs of improvement with decreasing oxygen requirement. On day 7 , however, she developed recurrent episodes of focal seizures involving both eyes and upper left lip. No immediate correctable cause was found on blood investigations and a drug chart review. Electroencephalography (EEG) showed a generalized burst suppression pattern with abnormal interictal comatose state. Her seizures were alleviated with leviteracetam and phenytoin along with a midazolam infusion. ACT of the brain showed no significant abnormality. However, an MRI of the brain done later on showed symmetrical areas of altered signal intensity appearing hyperintense on T2/fluid-attenuated inversion recovery sequences involving bilateral thalamic nuclei, midbrain, and pons, suggestive of encephalitis [Figure 2]. Ceftriaxone and vancomycin were added on suspicion of bacterial meningitis. Acyclovir was also added empirically and later withdrawn once the herpes simplex results were found to be negative. The CSF analysis showed a liquor white blood cell count of 30 , with neutrophils of $70 \%$, lymphocytes of $15 \%$, and mononuclear cells of $15 \%$. The protein CSF content was 292 and the CSF glucose was $69 \mathrm{mg} / \mathrm{dl}$ with corresponding blood sugars being $111 \mathrm{mg} / \mathrm{dl}$. CSF tests for cryptoccal antigens, an India ink preparation, HSV antigens, and cultures were all negative.

She was given sedation vacation but then was found to be in a confused state with intermittent agitation and maximum response of $\mathrm{E}_{4} \mathrm{M}_{4} \mathrm{Vt}$ on Glasgow Coma Scale (GCS).

No correctable cause was found. On day 13, a repeat MRI brain was done which showed a significant reduction of

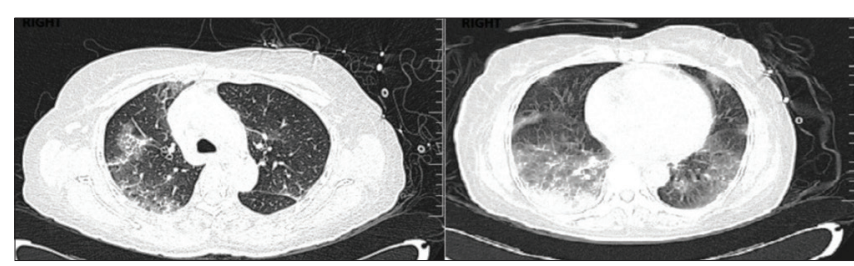

Figure 1: High-resolution computed tomography chest showing multiple areas of crazy paving and dense consolidation in the right lower lobe

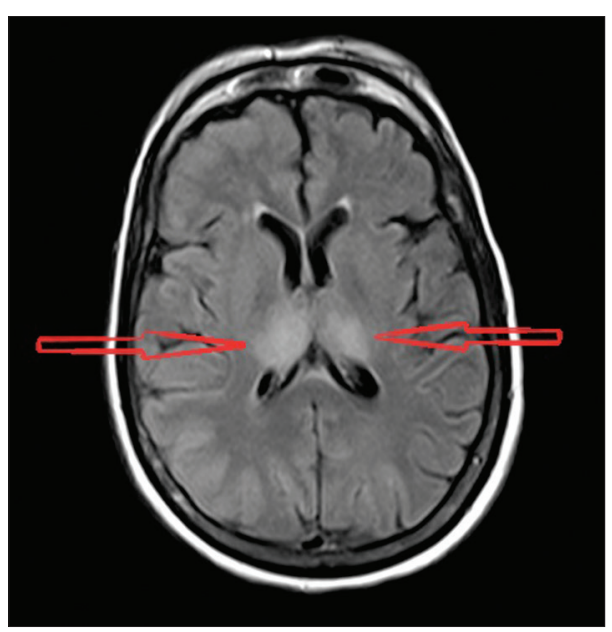

Figure 2: Magnetic resonance imaging brain showing symmetrical areas of altered signal intensity appearing hyperintense on T2/fluid attenuation inversion recovery involving bilateral thalami

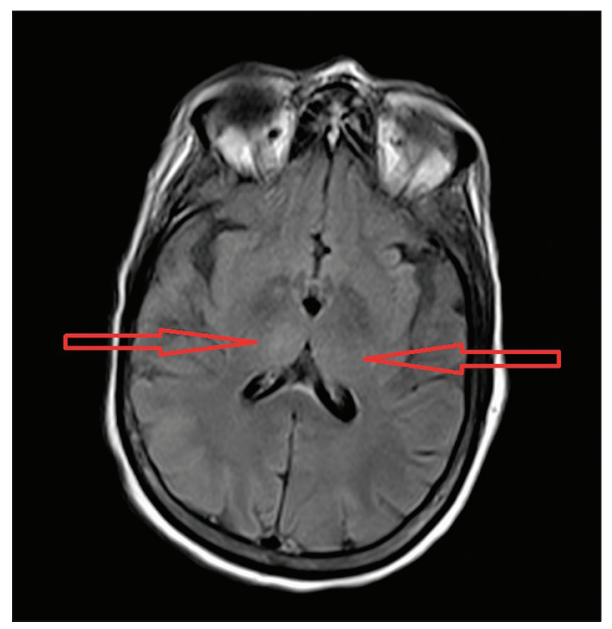

Figure 3: Repeat magnetic resonance imaging brain showing a significant reduction in abnormal signal in the affected areas

abnormal signaling in the affected areas [Figure 3]. A repeat EEG was done which was suggestive of a generalized encephalopathy [Figure 4].

Tracheotomy was done and the patient continued to be in an encephalopathic state with fluctuating sensorium, between $\mathrm{E}_{3} \mathrm{M}_{4} \mathrm{~V}_{\mathrm{T}}$ and $\mathrm{E}_{4} \mathrm{M}_{5} \mathrm{~V}_{\mathrm{T}}$, and gave no meaningful eye contact. She was slowly weaned off ventilatory support over the next week. She was discharged after 29 days of admission with her tracheostomy in situ. At her time of discharge, she was still in 


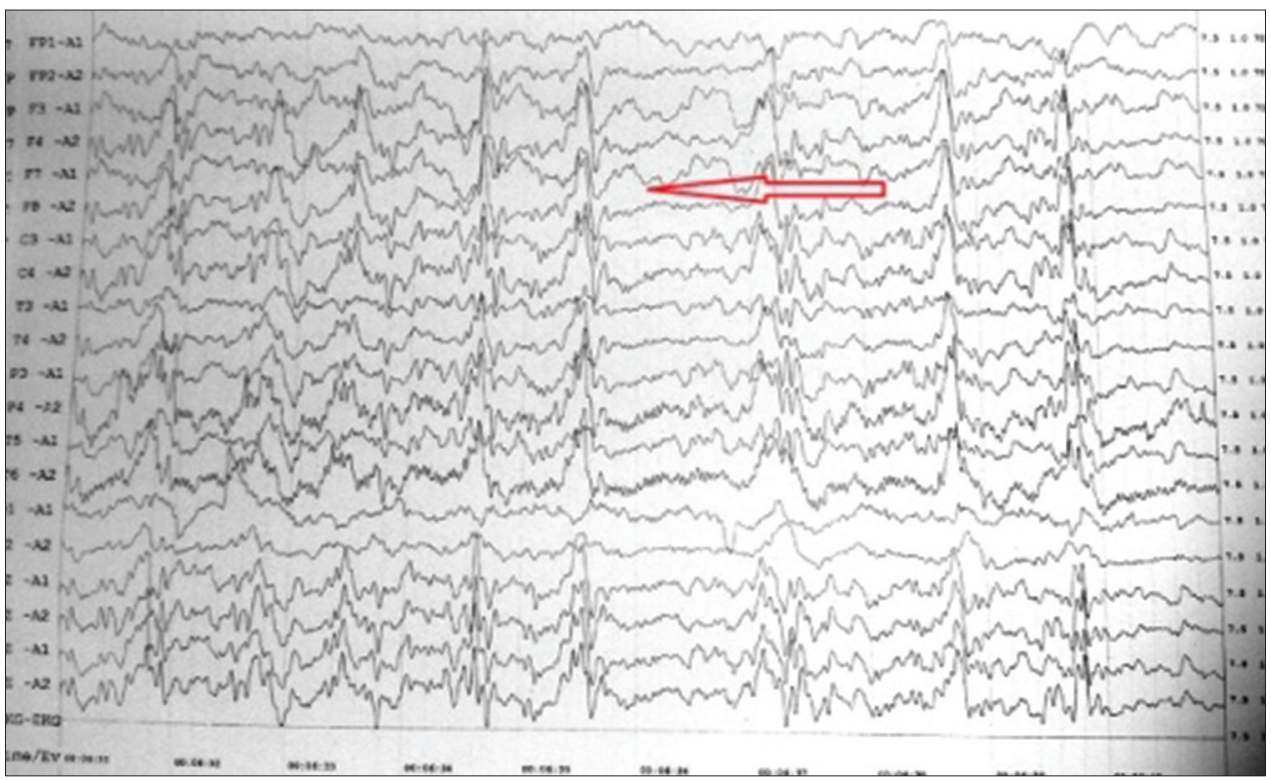

Figure 4: Electroencephalography suggestive of generalized encephalopathy

a confusional state with no meaningful eye contact, having a GCS of $\mathrm{E}_{4} \mathrm{M}_{5} \mathrm{~V}_{\mathrm{T}}$.

\section{Discussion}

Seasonal influenza-related neurological manifestations have been reported in literature before. CNS complications may manifest as encephalopathy, seizures, and Guillain-Barré syndrome. ${ }^{[5-8]}$ Acute influenza-related encephalopathy/encephalitis is a syndrome characterized primarily by symptoms associated with a rapidly progressive consciousness disorder in influenza patients. The true pathogenesis of influenza-associated neurologic disease remains unclear as influenza RNA is rarely detected in the CSF of encephalopathic patients. ${ }^{[9]}$ High levels of pro-inflammatory cytokines (such as interleukin-6 or tumor necrosis factor alpha) have been demonstrated in the serum and the CSF of children. ${ }^{[10]}$

Acute encephalitis and encephalopathy appear to be very variable in severity, ranging from case reports showing no residual sequelae to severe residual signs and symptoms. There is also a subset of patients who follow a malignant clinical course characterized by high morbidity and mortality. ${ }^{[1-14]}$ Our patient here did have significant residual neurological manifestations. Three out of four patients in a CDC report had abnormal EEG. ${ }^{[15]}$

Kimura et al. divided influenza-related brain changes into five categories based on the MR imaging and CT findings: (1) normal, (2) diffuse involvement of the cerebral cortex, (3) diffuse brain edema, (4) symmetric involvement of the thalamus, and (5) postinfectious focal encephalitis. ${ }^{[14]}$ Our patient probably fell in category 4 with bilateral symmetrical involvement of the thalamic nuclei, midbrain, and pons, reflecting hyperpermeability of the cerebral blood vessels followed by severe edema with or without micro hemorrhages. ${ }^{[12]}$

In a study on patients with influenza-associated encephalopathy/encephalitis, Meijer et al. found influenza virus in the CSF in just $5(16 \%)$ out of 32 patients. In the same study, the CSF analyses done in 38 patients were found to be abnormal in $26(68 \%)$. An elevated white blood cell count and an elevated protein concentration were observed most commonly, in 16 and 9 patients, respectively. ${ }^{[9]} \mathrm{We}$ could not send CSF for influenza virus isolation because of nonavailability. CSF routine analysis was more in favor of viral encephalitis in our case

\section{Conclusion}

To the best of our knowledge, there are very few case reports of adult H1N1 influenza-related encephalitis reported worldwide. ${ }^{[3]}$ This case report could serve to remind the clinician of the existence of adult H1N1 influenza-related encephalitis, especially in patients presenting with altered behavior in the setting of H1N1 influenza.

\section{Financial support and sponsorship}

Nil.

\section{Conflicts of interest}

There are no conflicts of interest.

\section{RefEREnCES}

1. Rothberg MB, Haessler SD. Complications of seasonal and pandemic influenza. Crit Care Med 2010;38:e91-7.

2. Glaser CA, Winter K, DuBray K, Harriman K, Uyeki TM, Sejvar J, et al. A population-based study of neurologic manifestations of severe influenza A (H1N1) pdm09 in California. Clin Infect Dis 2012;55:514-20

3. Gu Y, Shimada T, Yasui Y, Tada Y, Kaku M, Okabe N, et al. National surveillance of influenza-associated encephalopathy in Japan over six 
years, before and during the 2009-2010 influenza pandemic. PLoS One 2013;8:e54786.

4. Bengualid V, Berger J. Neurologic complications of acute influenza in adults: Case report and review of the literature. J Neurosci Clin Res 2017;2:1.

5. Togashi T, Matsuzono Y, Narita M, Morishima T. Influenza-associated acute encephalopathy in Japanese children in 1994-2002. Virus Res 2004;103:75-8.

6. Maricich SM, Neul JL, Lotze TE, Cazacu AC, Uyeki TM, Demmler GJ, et al. Neurologic complications associated with influenza A in children during the 2003-2004 influenza season in Houston, Texas. Pediatrics 2004;114:e626-33.

7. Price DA, Postlethwaite RJ, Longson M. Influenzavirus A2 infections presenting with febril convulsions and gastrointestinal symptoms in young children. Clin Pediatr (Phila) 1976;15:361-7.

8. Studahl M. Influenza virus and CNS manifestations. J Clin Virol 2003;28:225-32.

9. Meijer WJ, Linn FH, Wensing AM, Leavis HL, van Riel D, Geurts van Kessel $\mathrm{CH}$, et al. Acute influenza virus-associated encephalitis and encephalopathy in adults: A challenging diagnosis. JMM Case Rep 2016;3:e005076.
10. Fukumoto Y, Okumura A, Hayakawa F, Suzuki M, Kato T, Watanabe K, et al. Serum levels of cytokines and EEG findings in children with influenza associated with mild neurological complications. Brain Dev 2007;29:425-30.

11. Centers for Disease Control and Prevention. Neurologic complications associated with novel influenza A (H1N1) virus infection in children - Dallas, Texas, May 2009. MMWR Morb Mortal Wkly Rep 2009;58:773-8.

12. Chen YC, Lo CP, Chang TP. Novel influenza A (H1N1)-associated encephalopathy/encephalitis with severe neurological sequelae and unique image features - A case report. J Neurol Sci 2010;298:110-3.

13. Akins PT, Belko J, Uyeki TM, Axelrod Y, Lee KK, Silverthorn J, et al. H1N1 encephalitis with malignant edema and review of neurologic complications from influenza. Neurocrit Care 2010;13:396-406.

14. Kimura S, Ohtuki N, Nezu A, Tanaka M, Takeshita S. Clinical and radiological variability of influenza-related encephalopathy or encephalitis. Acta Paediatr Jpn 1998;40:264-70.

15. Fujimoto S, Kobayashi M, Uemura O, Iwasa M, Ando T, Katoh T, et al. PCR on cerebrospinal fluid to show influenza-associated acute encephalopathy or encephalitis. Lancet 1998;352:873-5. 